\title{
Factors Related to Standing Balance in Patients With Knee Osteoarthritis
}

\author{
Hye Jeong Park, MD, Saebyuk Ko, MD, Hyeon Mi Hong, MD, Eunjae Ok, MD, Jong In Lee, MD \\ Department of Rehabilitation Medicine, Seoul St. Mary's Hospital, The Catholic University of \\ Korea College of Medicine, Seoul, Korea
}

Objective To assess factors related to standing balance in patients with knee osteoarthritis (OA). Methods In total, 37 female patients with painful knee OA were included. Pain, knee alignment, and Kellgren and Lawrence grade were evaluated accordingly. Static standing balance was measured with a force-platform system under two different conditions: static standing with eyes open (EO) and eyes closed (EC) for 30 seconds. The mean speed $(\mathrm{mm} / \mathrm{s})$ of movement of the center of pressure in the anteroposterior (AP) and mediolateral directions and the mean velocity moment $\left(\mathrm{mm}^{2} / \mathrm{s}\right)$ were analyzed for assessment of static balance.

Results In the univariate regression analysis, age and knee alignment showed statistically significant relationships with the mean speed in the AP directions with EO. In the multiple linear regression model, age and knee alignment were positively associated and disease severity was negatively associated with mean speed in the AP directions with EO. However, the variables for EC static measurements were not significantly correlated with age, pain, knee alignment, or radiographic severity ( $\mathrm{p}>0.05)$.

Conclusion These findings show that the worse balance was associated with advanced age, less varus knee malalignment, and mild radiographic changes. Pain was not associated with standing balance.

Keywords Knee, Osteoarthritis, Balance

\section{INTRODUCTION}

Knee osteoarthritis (OA) is a common musculoskeletal disease found within increasing age [1]. Indeed, the condition is a leading cause of chronic disability in elderly

Received July 23, 2012; Accepted December 3, 2012

Corresponding author: Jong In Lee

Department of Rehabilitation Medicine, Seoul St. Mary's Hospital, The Catholic University of Korea College of Medicine, 505 Banpo-dong, Seocho-gu, Seoul 137-701, Korea

Tel: +82-2-2258-6283, Fax: +82-2-2258-2825, E-mail: ljikyh@catholic.ac.kr

(a) This is an open-access article distributed under the terms of the Creative Commons Attribution Non-Commercial License (http://creativecommons. org/licenses/by-nc/3.0) which permits unrestricted noncommercial use, distribution, and reproduction in any medium, provided the original work is properly cited.

Copyright $\odot 2013$ by Korean Academy of Rehabilitation Medicine persons [2]. Kim et al. [3] reported that the prevalence of radiographic knee $\mathrm{OA}$ was $37.3 \%$ and that of symptomatic knee OA was $24.2 \%$ in elderly community residents in Korea. Knee OA negatively affects physical functioning and quality of life for each patient and results in a serious economic burden to the society due to its high prevalence $[4,5]$.

Balance function is an important indicator of physical function and risk of falls [6]. Balance is controlled by multiple sensory inputs from visual, vestibular, and proprioceptive pathways, central processing, and neuromuscular responses [7]. Deterioration in balance may be accompanied by reduced function in any sensory system, declining neuromuscular responses, or problems in central processing. Age-related deterioration in balance can 
contribute to decreased independence, with increased fear and frequency of falls in elderly persons [8].

Patients with knee OA typically have impairment of proprioception within the joint or weakness in the quadriceps muscles as compared with those without knee OA. These impairments associated with the disease may explain the poorer balances within these patients $[6,9,10]$.

A recent study showed that knee alignment, knee pain intensity, quadriceps strength, and disease severity were all predictors of single-leg standing balance in individuals with medial knee OA [6]. However, reported studies on factors related to standing balance in patients with knee OA are rare in Korea. The purpose of this study is to identify factors related to standing balance in patients with knee OA.

\section{MATERIALS AND METHODS}

\section{Subjects}

This study was designed as a cross-sectional study. Among female patients over ages of 50 who had visited our outpatient department from June 2009 through February 2010, such subjects who were diagnosed with unilateral or bilateral knee OA based on the American College of Rheumatology criteria and who performed balance tests were included. In cases of bilateral knee OA, the more symptomatic leg was selected. Subjects were excluded for the following reasons: any history of previous lower extremity surgery, symptomatic diseases of other weight-bearing joints (hip, ankle, foot), and any neurological or systemic pathology that would influence balance or knee injection within 2 months. This study was approved by the Institutional Review Board at our hospital.

\section{Methods}

\section{Measurement of pain levels}

Pain levels were measured before the balance test using a Numerical Pain Rating Scale which questioned current pain levels.

\section{Radiographic analysis}

Knee alignment and OA severity were assessed using a weight-bearing anteroposterior (AP) radiograph of the knee in full extension. The method of Moreland et al. [11] was used to assess anatomic knee alignment.
Mechanical knee alignment was extrapolated using the regression equation from Hinman et al. [12]: mechanical alignment $=0.915 \times($ anatomic alignment $)+13.895$. Values less than $180^{\circ}$ indicated varus alignment. Anatomic alignment was measured as the angle determined by the intersection of the femoral and tibial anatomic axes. The femoral anatomic axis was determined by drawing a line from the center of the tibial spines to a point located 10 $\mathrm{cm}$ proximal and midway between the medial and lateral femoral surfaces. With the same method, the line of the tibia anatomic axis was drawn from the center of the tibial spines to a point $10 \mathrm{~cm}$ distal and midway between the medial and lateral tibial surfaces. Radiographic severity was assessed using the Kellgren-Lawrence grade. All subjects were analyzed radiographically by an experienced radiologist in a blinded manner.

\section{Balance measurements}

Force-platform balance test data were obtained using the Good Balance System (Metitur Ltd., Jyvāskylā, Finland). This system consists of a triangular force platform, a three-channel amplifier with an analog-to-digital converter, and a computer program. The sampling frequency was $50 \mathrm{~Hz}$.

Balance was examined under two different conditions: 1) static standing with eyes open (EO) for 30 seconds and 2) static standing with eyes closed (EC) for 30 seconds. Prior to the actual tests, all participants repeated three practice tests to eliminate any learning effect and assure familiarity with the procedure. To increase reliability, it has been recommended that these tests be performed on at least two occasions [13]. Thus, tests were performed three times with a 1minute break between tests. The mean value of the three repetitions of each test was used for analysis. In each test, patients gazed at a point marked on the wall at eye level and stood on the force platform with their feet positioned shoulder-width apart and their arms comfortably by their sides. To prevent any stimulation of cutaneous receptors, all subjects were required to wear shorts and were bare-footed. To prevent abrupt postural sway due to auditory stimuli, the tests were conducted in a quiet environment.

Outcome variables for static posturography were 1) the mean speed of the center of pressure (COP) movement in the AP directions $(\mathrm{mm} / \mathrm{s}), 2)$ the mean speed of COP movement in the mediolateral $(\mathrm{ML})$ directions $(\mathrm{mm} / \mathrm{s})$, 
and 3) the mean velocity moment $\left(\mathrm{mm}^{2} / \mathrm{s}\right)$, calculated as the mean area of COP movement during each second of the test. To avoid errors caused by height differences, the values of the original AP and ML speed variables were adjusted by dividing the values by the participant's height $(\mathrm{cm})$ and multiplying by 180 (constant), as in the previous study [14]. The values of velocity moment were also adjusted by dividing the original value by height ${ }^{2}$ and multiplying by $180^{2}$.

\section{Statistical analysis}

The SPSS ver. 11.5 (SPSS Inc., Chicago, IL, USA) was used for all statistical analyses. A $\mathrm{p}<0.05$ was considered to indicate statistical significances. To correct the variance of the balance-test variables (mean speeds, velocity moment), we used a logarithmic transformation. Univariate regression analysis was performed to assess the effects of age, pain, knee alignment, and radiographic se-

Table 1. Baseline characteristics of subjects $(n=37)$

\begin{tabular}{lc}
\multicolumn{1}{c}{ Characteristic } & Value \\
\hline Age (yr) & $56.4 \pm 4.5$ \\
Pain $^{\text {a) }}$ & $3.2 \pm 0.7$ \\
Alignment $\left.^{(\circ}\right)^{\text {b) }}$ & $176.8 \pm 2.5$ \\
Disease severity & \\
Mild (K/L grade 1-2) & 24 \\
\hline Moderate/severe (K/L grade 3-4) & 13 \\
\hline
\end{tabular}

Values are presented as mean \pm standard deviation or the number of cases.

K/L, Kellgren-Lawrence.

${ }^{\text {a)}}$ Pain scores are reported with a numerical rating scale from 0 to $10 .{ }^{\text {b) }}$ Values less than $180^{\circ}$ indicate varus alignment, whereas values greater than $180^{\circ}$ indicate valgus alignment.

Table 2. Results of static posturography with eyes open and closed

\begin{tabular}{lcc}
\hline \multicolumn{1}{c}{ Variable } & Eyes open & Eyes closed \\
\hline $\begin{array}{l}\text { Mean speed in the } \\
\text { mediolateral directions } \\
(\mathrm{mm} / \mathrm{s})\end{array}$ & $0.54 \pm 0.14$ & $0.60 \pm 0.15$ \\
$\begin{array}{l}\text { Mean speed in the } \\
\text { anteroposterior directions } \\
(\mathrm{mm} / \mathrm{s})\end{array}$ & $0.81 \pm 0.10$ & $1.00 \pm 0.11$ \\
$\begin{array}{l}\text { Mean velocity moment } \\
\left(\mathrm{mm}^{2} / \mathrm{s}\right)\end{array}$ & $1.04 \pm 0.20$ & $1.19 \pm 0.23$ \\
\hline
\end{tabular}

Values are mean \pm standard deviation. verity on the outcome variables for static posturography. Then, a step-wise multiple linear regression analysis was performed to select an appropriate model, and $\mathrm{p}>0.1$ was used as a criterion for removing variables.

\section{RESULTS}

In total, 37 female patients were enrolled. The mean height of subjects was $154.7 \pm 4.7 \mathrm{~cm}$, and their mean weight was $57.9 \pm 7.2 \mathrm{~kg}$. The baseline characteristics of the 37 subjects are provided in Table 1. Table 2 shows the results of static posturography with EO and EC. In the univariate regression analysis, age and knee alignment showed statistically significant relationships with the mean speed in the AP directions with EO (Table 3). In the final multiple linear regression model, age and knee alignment were positively associated and disease severity was negatively associated with the mean speed in the AP directions with EO (Table 4). However, pain was not associated with any outcome variables for static posturography. The mean speed in the ML directions and the mean velocity moment with EO were not significantly correlated with age, pain, knee alignment, or radiographic severity ( $p>0.05$ ). The variables for EC static measurements were also not significantly correlated with age, pain, knee

Table 3. Associations of the mean speed in the anteroposterior directions with eyes open with variables by univariate linear regression analyses

\begin{tabular}{lcc}
\multicolumn{1}{c}{ Variable } & $\beta \pm$ standard error & p-value \\
\hline Age $(\mathrm{yr})$ & $0.01 \pm 0.003$ & 0.005 \\
Pain & $-0.01 \pm 0.02$ & 0.570 \\
Alignment $\left({ }^{\circ}\right)$ & $0.013 \pm 0.006$ & 0.042 \\
Disease severity $^{\text {a) }}$ & $-0.04 \pm 0.03$ & 0.231 \\
\hline
\end{tabular}

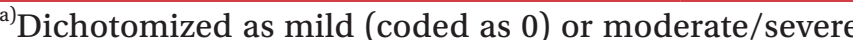
(coded as 1).

Table 4. Associations of the mean speed in the anteroposterior directions with eyes open with variables by multiple linear regression analyses

\begin{tabular}{lcc}
\hline \multicolumn{1}{c}{ Variable } & $\beta \pm$ standard error & p-value \\
\hline Age $(\mathrm{yr})$ & $0.011 \pm 0.003$ & 0.001 \\
Alignment $\left(^{\circ}\right)$ & $0.012 \pm 0.005$ & 0.041 \\
Disease severity & $-0.067 \pm 0.029$ & 0.028 \\
\hline Model: $\mathrm{R}^{2}=0.39, \mathrm{p}<0.01$. & \\
a) Dichotomized as mild (coded as 0 ) or moderate/severe
\end{tabular}

(coded as 1) 
alignment, or radiographic severity ( $\mathrm{p}>0.05)$.

\section{DISCUSSION}

About $30 \%$ of people aged 65 or more fall at least once per year, and half of such falls lead to injuries. Falls bring negative results, such as disability, loss of mobility, poor quality of life, and emotional fear of falling again $[15,16]$. Postural instability is a risk factor for falls $[17,18]$. Balance can be assessed in a number of different ways. The most widely used method is the static-force platform balance [17-19]. A recent prospective study showed that indoor fallers had greater COP movements as compared with non-fallers. Moreover, static-force platform balance tests provide valid information on postural controls that can be used to predict fall risks among older individuals [17].

Balance function is typically impaired in advanced age with or without knee OA $[6,14]$. Our results indicated agerelated deterioration in balance, consistent with previous studies. Age-related deterioration in balance starts at a young age and accelerates above the age of 60 [14]. Altered sensory function and biomechanical or central processing can contribute to diminished balance control in elderly persons [20,21]. Previous studies of standing balance have shown various relationships between pain and balance. Some studies revealed that better standing balance was related to less knee pains [6,22-24]. However, Masui et al. [25] indicated no relationships between pain and balance. Also, reduced knee pain did not result in improved postural stability, although reduced knee pains did result in increased maximal voluntary contraction [26]. Our results showed no significant correlations between pain and standing balance. However, the average pain intensity in our study was mild to moderate and within a narrow range. So, interpretation of the regression analysis should be made cautiously.

A few previous studies showed contradictory relationships between knee alignment and balance. Hunt et al. [6] showed that better standing balance was related to less varus malalignment. They suggested that neuromuscular control was compromised in the presence of malalignment, possibly due to reduced joint innervations or muscle reflexes [6,27]. In contrast, Lim et al. [28] showed that greater varus malalignment was associated with increased quadriceps strength and improved step test performance (a measure of dynamic standing balance).
Our results were consistent with these findings, although we used a static balance test. It could not be clearly explained why patients with varus malalignment performed better on the step test. They presumed that the improved step test performances in patients with greater varus malalignment could be explained by greater quadriceps strength relative to patients with less malalignment.

Kim et al. [19] found more balance deficits in patients with moderate to severe knee OA than in those with mild diseases. In contrast, Hunt et al. [6] showed that worse standing balance was related to mild radiographic changes. They suggested that higher levels of co-contraction of the hamstrings and quadriceps muscles in patients with more advanced disease could result in a more rigid lower extremity, which actually increased joint stability and balance. Our results are consistent with the previous study by Hunt et al. [6].

Our study has several limitations. First, the sample was small and consisted of only female patients, so these result are not representative for all patients with knee OA. Second, the ability to transfer these results to functional situations is limited because we only assessed static standing balance. Dynamic balance tests that predict the risk of falls better should be included in future studies. Third, most of patients had varus knees, and the range of extremity alignments was small, so the alignment may not have sufficiently affected balance. Further studies including a wide range of extremity alignments and valgus knees are also needed. Finally, we assessed postural sway with subjects standing on both legs; thus, balance tests may have been influenced by the contralateral knee.

In conclusion, our results suggested that worse balance was associated with advanced age, less varus malalignment, and mild radiographic changes. However, pain was not associated with standing balance. Until today, previous studies showed inconsistent relations between balance and pain, knee alignment or radiographic severity. As a result, the ability to transfer our findings to clinical situation is limited. More research in this area will be needed.

\section{CONFLICT OF INTEREST}

No potential conflict of interest relevant to this article was reported. 


\section{REFERENCES}

1. Felson DT, Zhang Y. An update on the epidemiology of knee and hip osteoarthritis with a view to prevention. Arthritis Rheum 1998;41:1343-55.

2. Guccione AA, Felson DT, Anderson JJ, Anthony JM, Zhang Y, Wilson PW, et al. The effects of specific medical conditions on the functional limitations of elders in the Framingham Study. Am J Public Health 1994;84:351-8.

3. Kim I, Kim HA, Seo YI, Song YW, Jeong JY, Kim DH. The prevalence of knee osteoarthritis in elderly community residents in Korea. J Korean Med Sci 2010;25:293-8.

4. Kim IJ, Kim HA, Seo YI, Song YW, Hunter DJ, Jeong JY, et al. Tibiofemoral osteoarthritis affects quality of life and function in elderly Koreans, with women more adversely affected than men. BMC Musculoskelet Disord 2010;11:129.

5. Bitton R. The economic burden of osteoarthritis. Am J Manag Care 2009;15(8 Suppl):S230-5.

6. Hunt MA, McManus FJ, Hinman RS, Bennell KL. Predictors of single-leg standing balance in individuals with medial knee osteoarthritis. Arthritis Care Res 2010;62:496-500.

7. Wegener L, Kisner C, Nichols D. Static and dynamic balance responses in persons with bilateral knee osteoarthritis. J Orthop Sports Phys Ther 1997;25:13-8.

8. Hurley MV, Rees J, Newham DJ. Quadriceps function, proprioceptive acuity and functional performance in healthy young, middle-aged and elderly subjects. Age Ageing 1998;27:55-62.

9. Slemenda C, Brandt KD, Heilman DK, Mazzuca S, Braunstein EM, Katz BP, et al. Quadriceps weakness and osteoarthritis of the knee. Ann Intern Med 1997;127:97-104.

10. Koralewicz LM, Engh GA. Comparison of proprioception in arthritic and age-matched normal knees. J Bone Joint Surg Am 2000;82:1582-8.

11. Moreland JR, Bassett LW, Hanker GJ. Radiographic analysis of the axial alignment of the lower extremity. J Bone Joint Surg Am 1987;69:745-9.

12. Hinman RS, May RL, Crossley KM. Is there an alternative to the full-leg radiograph for determining knee joint alignment in osteoarthritis? Arthritis Rheum 2006;55:306-13.
13. Clark S, Rose DJ, Fujimoto K. Generalizability of the limits of stability test in the evaluation of dynamic balance among older adults. Arch Phys Med Rehabil 1997;78:1078-84.

14. Era P, Sainio P, Koskinen S, Haavisto P, Vaara M, Aromaa A. Postural balance in a random sample of 7,979 subjects aged 30 years and over. Gerontology 2006;52:204-13.

15. Close J, Ellis M, Hooper R, Glucksman E, Jackson S, Swift C. Prevention of falls in the elderly trial (PROFET): a randomised controlled trial. Lancet 1999;353:93-7.

16. Kwan MM, Close JC, Wong AK, Lord SR. Falls incidence, risk factors, and consequences in Chinese older people: a systematic review. J Am Geriatr Soc 2011;59:536-43.

17. Pajala S, Era P, Koskenvuo M, Kaprio J, Törmäkangas T, Rantanen T. Force platform balance measures as predictors of indoor and outdoor falls in communitydwelling women aged 63-76 years. J Gerontol A Biol Sci Med Sci 2008;63:171-8.

18. Piirtola M, Era P. Force platform measurements as predictors of falls among older people: a review. Gerontology 2006;52:1-16.

19. Kim HS, Yun DH, Yoo SD, Kim DH, Jeong YS, Yun JS, et al. Balance control and knee osteoarthritis severity. Ann Rehabil Med 2011;35:701-9.

20. Whipple R, Wolfson L, Derby C, Singh D, Tobin J. Altered sensory function and balance in older persons. J Gerontol 1993;48:71-6.

21. Wolfson L, Whipple R, Derby CA, Amerman P, Murphy T, Tobin JN, et al. A dynamic posturography study of balance in healthy elderly. Neurology 1992;42:206975.

22. Hall MC, Mockett SP, Doherty M. Relative impact of radiographic osteoarthritis and pain on quadriceps strength, proprioception, static postural sway and lower limb function. Ann Rheum Dis 2006;65:865-70.

23. Hinman RS, Bennell KL, Metcalf BR, Crossley KM. Balance impairments in individuals with symptomatic knee osteoarthritis: a comparison with matched controls using clinical tests. Rheumatology 2002;41:138894.

24. Jadelis K, Miller ME, Ettinger WH Jr, Messier SP. Strength, balance, and the modifying effects of obesity and knee pain: results from the Observational 
Arthritis Study in Seniors (oasis). J Am Geriatr Soc 2001;49:884-91.

25. Masui T, Hasegawa Y, Yamaguchi J, Kanoh T, Ishiguro $\mathrm{N}$, Suzuki S. Increasing postural sway in rural-community-dwelling elderly persons with knee osteoarthritis. J Orthop Sci 2006;11:353-8.

26. Hassan BS, Doherty SA, Mockett S, Doherty M. Effect of pain reduction on postural sway, proprioception, and quadriceps strength in subjects with knee osteoarthritis. Ann Rheum Dis 2002;61:422-8.

27. Salo P. The role of joint innervation in the pathogenesis of arthritis. Can J Surg 1999;42:91-100.

28. Lim BW, Hinman RS, Wrigley TV, Bennell KL. Varus malalignment and its association with impairments and functional limitations in medial knee osteoarthritis. Arthritis Rheum 2008;59:935-42. 